\title{
Eight-year results after aortic valve replacement with the Freestyle stentless bioprosthesis
}

\author{
David S. Bach, MDa \\ Neal D. Kon, MD ${ }^{\mathrm{b}}$ \\ Jean G. Dumesnil, $M^{\mathrm{C}}$ \\ Colleen F. Sintek, MD ${ }^{d}$ \\ Donald B. Doty, MD
}

From the Department of Medicine, ${ }^{a}$ Division of Cardiology, University of Michigan, Ann Arbor, Mich; the Department of Surgery, ${ }^{\mathrm{b}}$ Section of Cardiothoracic Surgery, Bowman Gray School of Medicine, Winston-Salem, NC; the Department of Medicine, ${ }^{\mathrm{c}}$ Division of Cardiology, University Laval, Ste-Foy, Quebec, Canada; the Department of Cardiac Surgery, ${ }^{\mathrm{d}}$ Kaiser Permanente Hospital, Los Angeles, Calif; and LDS Hospital, ${ }^{\text {e }}$ Salt Lake City, Utah.

Received for publication Oct 7, 2003; revisions requested Dec 28, 2003; accepted for publication Jan 13, 2004.

Address for reprints: David S. Bach, MD, L3119 Women's-0273, 1500 E Medical Center Dr, Ann Arbor, MI 48109 (E-mail: dbach@umich.edu).

J Thorac Cardiovasc Surg 2004;127: $1657-63$

$0022-5223 / \$ 30.00$

Copyright $\odot 2004$ by The American Association for Thoracic Surgery

doi:10.1016/j.jtcvs.2004.01.023
Objectives: We sought to describe the hemodynamic and clinical outcomes for the Freestyle aortic root bioprosthesis (Medtronic, Inc, Minneapolis, Minn) in a large multicenter cohort prospectively followed for 8 years.

Methods: A total of 700 patients (651 [93\%] $>60$ years of age) at 8 centers in North America were followed prospectively after aortic valve replacement with the Freestyle stentless bioprosthesis; the implant technique was subcoronary in 500, total root in 162, and root inclusion in 38. Follow-up was 3395 patient-years $(4.9 \pm 2.3$ years per patient). Clinical and echocardiographic follow-up was prospectively obtained at yearly intervals.

Results: For the subcoronary, total root, and root inclusion groups, actuarial freedom from valve-related death was 96.8\% (SE 3.0\%), 92.3\% (SE 7.7\%), and 90.9\% (SE $11.2 \%$ ), respectively, and freedom from structural deterioration was $98.6 \%$ (SE $2.0 \%$ ), $100.0 \%$ (SE 0.0\%), and $100.0 \%$ (SE 0.0\%), respectively. Hemodynamics remained excellent at 6 years. Freedom from moderate or more aortic regurgitation was $86.0 \%$ (SE 5.1\%), 98.7\% (SE 3.9\%), and 97.3\% (SE 6.6\%), respectively. Gradients were slightly lower $(P=.0009)$, and the effective orifice area $(P=.02)$ and freedom from aortic regurgitation were slightly higher $(P=.03)$ with total root than subcoronary implantation.

Conclusions: The Freestyle stentless aortic root bioprosthesis is a versatile option for aortic valve replacement. Measures of clinical outcomes and prosthesis durability remain excellent in multicenter follow-up through 8 years in a population predominantly older than 60 years at the time of the operation.

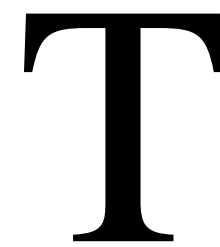

he Freestyle aortic root bioprosthesis (Medtronic, Inc, Minneapolis, Minn) is a stentless porcine aortic root prepared by using proprietary low-pressure and zero-pressure fixation processes and alpha-amino oleic acid leaflet anticalcification treatment, with the aim of optimizing both hemodynamics and bioprosthesis durability. The device can be implanted as a subcoronary or modified subcoronary valve replacement, as a complete aortic root replacement (total root), or as a root inclusion. Initial implantations in human subjects began in 1992, and the device has been approved for clinical use in the United States since 1997.

Previously published reports confirm excellent hemodynamics associated with the Freestyle stentless aortic root. ${ }^{1-5}$ However, as a bioprosthesis, its usefulness is affected by its durability. The stentless valve design and tissue anticalcification treatment might allow for significant mitigation of bioprosthesis calcification and structural valve failure, which has been supported in animal models ${ }^{6,7}$ and existing clinical studies. ${ }^{1,8}$ The purpose of the present report is to describe the hemodynamic 
TABLE 1. Valve sizes implanted

\begin{tabular}{lccc}
\hline & Subcoronary & Total root & Root inclusion \\
\hline $19 \mathrm{~mm}$ & $31(6.2 \%)$ & $8(4.9 \%)$ & $0(0 \%)$ \\
$21 \mathrm{~mm}$ & $103(20.6 \%)$ & $22(13.6 \%)$ & $4(10.5 \%)$ \\
$23 \mathrm{~mm}$ & $133(26.6 \%)$ & $33(20.4 \%)$ & $11(28.9 \%)$ \\
$25 \mathrm{~mm}$ & $137(27.4 \%)$ & $35(21.6 \%)$ & $13(34.2 \%)$ \\
$27 \mathrm{~mm}$ & $96(19.2 \%)$ & $64(39.5 \%)$ & $10(26.3 \%)$ \\
\hline
\end{tabular}

and clinical outcomes for the Freestyle aortic root bioprosthesis in a large multicenter cohort prospectively followed for up to 8 years.

\section{Patients and Methods Study Population}

The multicenter evaluation of the Freestyle stentless aortic root bioprosthesis began in 1992 at 21 centers in North America and Europe. In 1997, a long-term study of the valve began at 8 of these centers, which were selected for patient volume and protocol adherence. Study sites and clinical investigators are listed in the Appendix. The study protocol was reviewed and approved by each participating hospital's ethics review board; all subjects provided written informed consent. The long-term study group includes 700 consecutive patients; 651 (93\%) of 700 were older than 60 years at the time of the operation. The implant technique was subcoronary in $500(71.4 \%)$ patients, total root in $162(23.1 \%)$ patients, and root inclusion in $38(5.4 \%)$ patients. Most of the subcoronary implants were of the modified subcoronary variety, with retention of the noncoronary sinus of Valsalva. Demographic data and patient characteristics have been previously published. ${ }^{4}$ The operative technique has been previously described. ${ }^{1}$ The distribution of valve sizes is shown in Table 1. Follow-up was 3395 patient-years (mean, $4.9 \pm 2.3$ years per patient; range, 0-9 years).

\section{Clinical and Echocardiographic Data}

The collection of clinical and echocardiographic data has been previously described. ${ }^{1,4}$ In brief, preoperative clinical data and surgical data were prospectively recorded for each patient. Patients were prospectively monitored throughout the postoperative follow-up period for adverse events, following guidelines of the Society of Thoracic Surgeons and The American Association of Thoracic Surgeons. ${ }^{9}$ Both clinical and echocardiographic data were obtained at specified intervals of within 30 days of discharge, 3 to 6 months after the operation, 1 year after the operation, and yearly thereafter.

Echocardiograms were obtained at the respective investigational centers by using clinically standard criteria for analysis. The mean gradient was calculated by using the modified Bernoulli equation, correcting for proximal velocity. ${ }^{10}$ The effective orifice area (EOA) was calculated by using the continuity equation. ${ }^{10} \mathrm{Left}$ ventricular (LV) mass index was calculated as previously described by means of the modified American Society of Echocardiography cube method., ${ }^{411}$ Aortic regurgitation (AR) was graded as absent, trivial, mild, moderate, or severe on the basis of standard clinical criteria, including assessment of jet width, circumference, and eccentricity. ${ }^{12}$

\section{Statistical Methods}

Continuous data are expressed as means \pm 1 SD. Categoric data are expressed as percentages. Survival analyses with the KaplanMeier method were used to estimate survival, freedom from valverelated adverse events, and freedom from AR; the Peto formula was used to calculate the SE of the estimates. Cox proportional hazard models were used to test for differences in adverse events between patients undergoing implantation with the subcoronary and total root techniques and between patients with indexed EOAs of less than versus greater than or equal to $0.85 \mathrm{~cm}^{2} / \mathrm{m}^{2}$. Repeatedmeasures analysis of variance was performed to test for differences in LV mass index between patient populations. Statistical analysis was performed with SAS statistical software (SAS Institute, Inc, Cary, NC).

\section{Results \\ Clinical Outcomes}

Operative death for this population has been previously described. ${ }^{1,4}$ Actuarial survival and freedom from valverelated death through 8 years are shown in Figures 1 and 2 . For patients undergoing implantation with the subcoronary, total root, and root inclusion techniques, actuarial freedom from cardiac death at 8 years was $87.8 \%$ (SE 5.3\%), 88.0\% (SE 9.2\%), and 97.1\% (SE 6.7\%), respectively, and freedom from noncardiac death was $77.8 \%$ (SE 6.3\%), 78.3\% (SE $11.0 \%$ ), and $83.3 \%$ (SE $13.9 \%$ ), respectively. There were no significant differences between implantation techniques in overall survival $(P=.73)$ or freedom from valve-related death $(P=.63)$. Freedom from reoperation and freedom from structural valve deterioration are shown in Figures 3 and 4. There were no significant differences between implant groups in either freedom from reoperation $(P=.40)$ or freedom from structural valve deterioration $(P=1.00)$. Actual freedom from valve-related death at 8 years was 97.4\% (SE 0.8\%), 94.6\% (SE 3.6\%), and 91.5\% (SE 4.7\%) for the subcoronary, full root, and root inclusion groups, respectively. Actual freedom from cardiac death was $89.4 \%$ (SE 1.6\%), 88.9\% (SE 2.7\%), and 97.3 (SE 2.7\%); actual freedom from reoperation was $96.8 \%$ (SE 0.9\%), 98.7\% (SE $0.9 \%$ ), and $92.1 \%$ (SE 4.4\%); and actual freedom from structural valve deterioration was $99.0 \%$ (SE 0.6\%), $100.0 \%$ (SE $0.0 \%$ ), and $100.0 \%$ (SE $0.0 \%$ ), respectively.

There were a total of 3 cases of structural valve deterioration, all occurring in the subcoronary group. These occurred in association with right cusp tear in 2 cases, 28 months after implantation of a $21-\mathrm{mm}$ valve in a 77 -yearold woman, and 53 months after implantation of a $25-\mathrm{mm}$ valve in a 62-year-old woman. The third case occurred in association with left cusp dehiscence 82 months after implantation of a 25 -mm valve in a 62 -year-old man. There was no evidence of calcification in any of the 3 cases.

\section{Hemodynamics}

Hemodynamics by valve size early after surgical intervention have been previously reported. ${ }^{1,4}$ Mean gradients, 


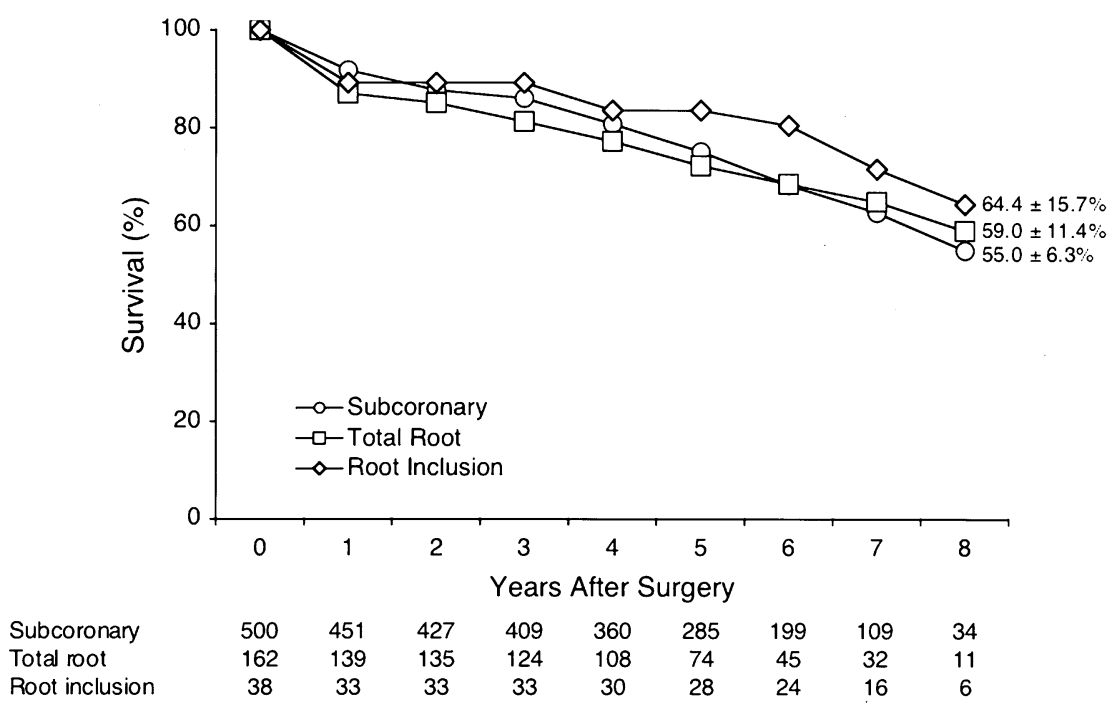

Figure 1. Survival through 8 years by implant technique. There were no apparent differences between implant techniques in overall survival $(P=.73)$. Data labels are presented as percentages $\pm S E$ at 8 years. Numbers below the graph represent patients at risk.

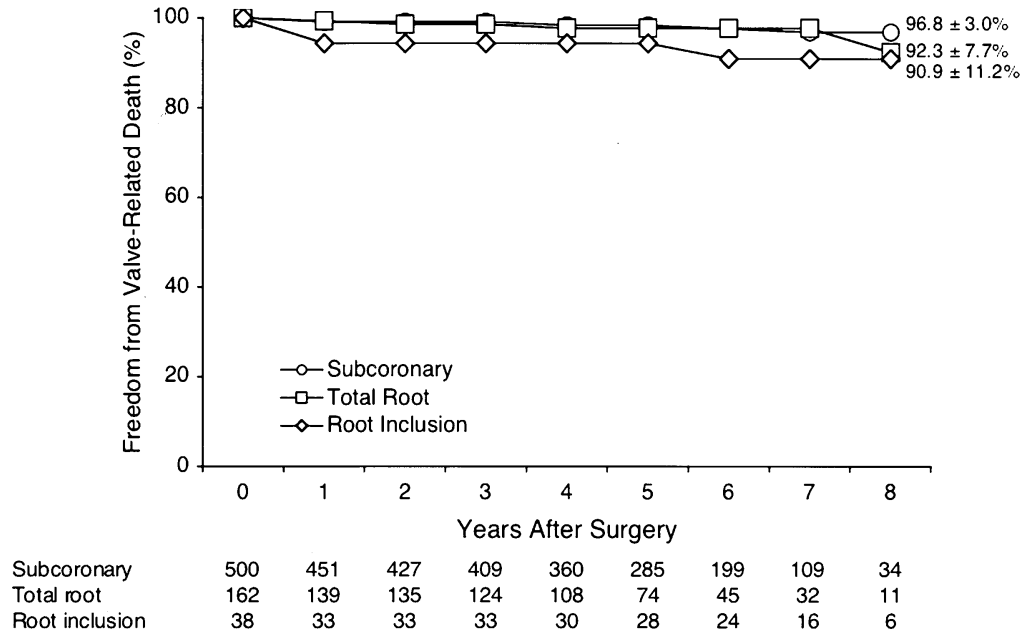

Figure 2. Freedom from valve-related death through 8 years by implant technique. There were no apparent differences between implant techniques in freedom from valve-related death $(P=.63)$. Data labels are presented as percentages \pm SE at 8 years. Numbers below the graph represent patients at risk.

EOA, and indexed EOA at 1 and 6 years after the operation are shown in Table 2. Gradients were lower $(P=.0001)$ and EOA was higher $(P=.0001)$ for larger than for smaller valve sizes. Gradients were lower $(P=.0009)$ and EOA was higher $(P=.02)$ among patients undergoing implantation by means of the total root technique than among those undergoing implantation by means the subcoronary technique. A decrease in mean gradient and increase in EOA from early to 1 year after the operation have been previously described. ${ }^{1,4}$ In the present analysis there was a small but statistically significant increase in mean gradient from 1 to
6 years after the operation among patients with available data at both 1 and 6 years, which is of doubtful clinical significance (subcoronary: $\mathrm{n}=143, \Delta=1.3 \pm 4.1 \mathrm{~mm} \mathrm{Hg}$, $P=.0001$; total root: $\mathrm{n}=37, \Delta=0.7 \pm 2.2 \mathrm{~mm} \mathrm{Hg}, P=$ $.05)$. There was an extremely small but statistically significant decrease in EOA between 1 and 6 years among subcoronary implants $\left(\mathrm{n}=139, \Delta=-0.1 \pm 0.4 \mathrm{~cm}^{2}, P=\right.$ .001 ) but no statistically significant change in EOA among patients undergoing full root $\left(\mathrm{n}=37, \Delta=-0.1 \pm 0.7 \mathrm{~cm}^{2}\right.$, $P=.6)$ or root inclusion $\left(\mathrm{n}=14, \Delta=-0.1 \pm 0.5 \mathrm{~cm}^{2}\right.$, $P=.5$ ) implantations. 


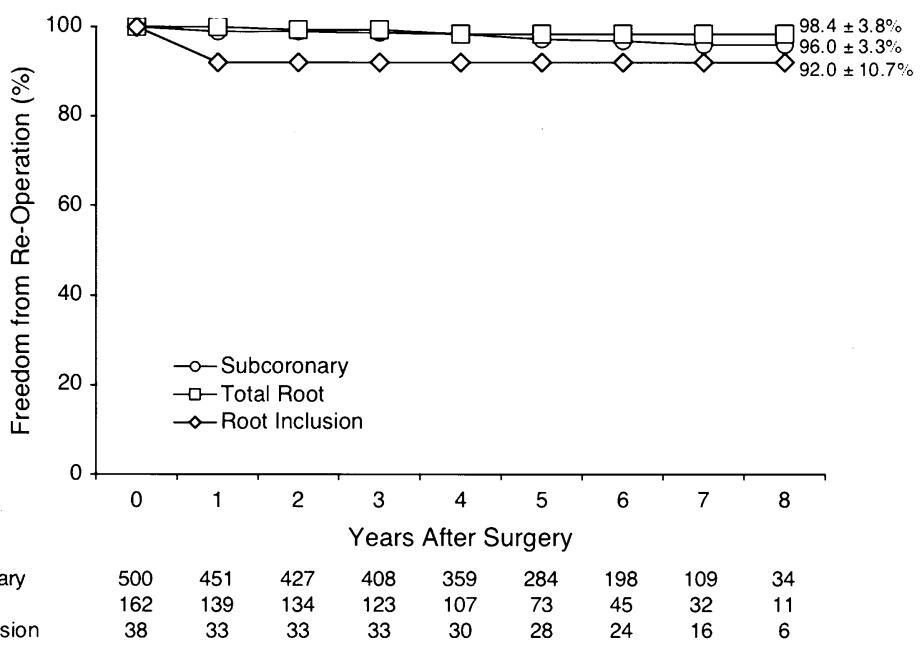

Figure 3. Freedom from reoperation through 8 years by implant technique. There were no apparent differences between implant techniques in freedom from reoperation $(P=.40)$. Data labels are presented as percentages \pm $\mathrm{SE}$ at 8 years. Numbers below the graph represent patients at risk.

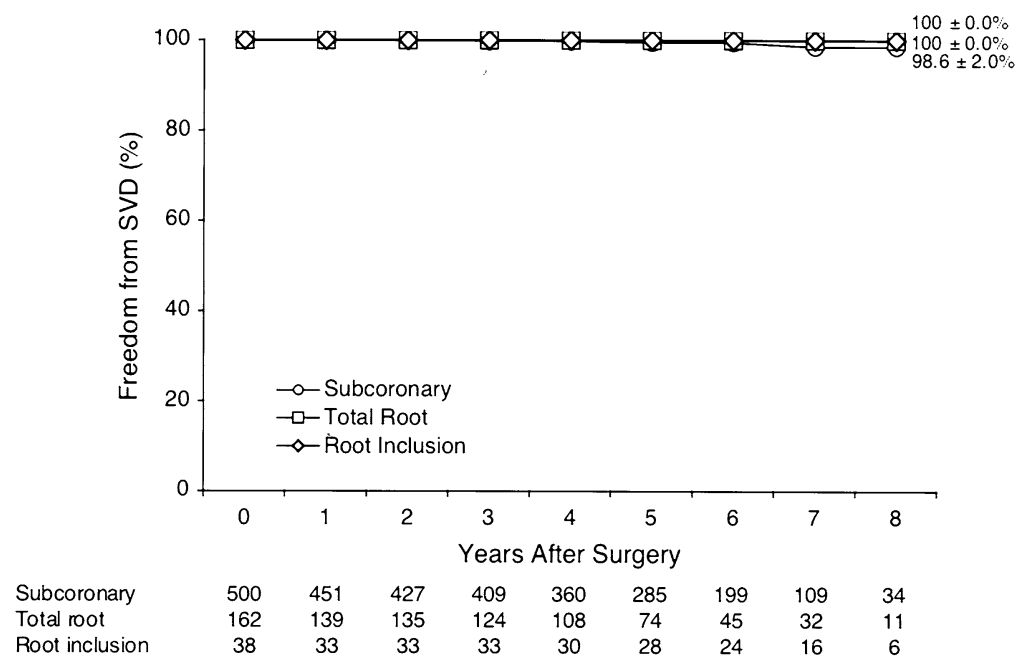

Figure 4. Freedom from structural valve deterioration through 8 years by implant technique. There were no apparent differences between implant techniques in freedom from structural valve deterioration $(P=1.00)$. Data labels are presented as percentages \pm SE at 8 years. Numbers below the graph represent patients at risk. SVD, Structural valve deterioration.

\section{Mass Index}

LV mass index over time is shown in Figure 5. LV mass index decreased significantly early after aortic valve replacement for all implant techniques. Between 1 and 6 years after the operation, there was a small but statistically significant increase in LV mass index. In the first year after the operation, there was greater decrease in LV mass index associated with larger than smaller valve sizes $(P=.01)$ and among patients without than with prosthesis-patient mismatch (indexed EOA, $<0.85 \mathrm{~cm}^{2} / \mathrm{m}^{2}$ ).

\section{Prosthesis-Patient Mismatch}

The prevalence of prosthesis-patient mismatch (defined as moderate for an indexed EOA of $<0.85 \mathrm{~cm}^{2} / \mathrm{m}^{2}$ or as severe for an indexed EOA of $\left.<0.65 \mathrm{~cm}^{2} / \mathrm{m}^{2}\right)^{13}$ is shown in Table 3 . The prevalence of prosthesis-patient mismatch decreased in the first year after the operation and was lower and remained lower through 6 years among patients who underwent total root aortic valve replacement. Analysis of matched data revealed that prosthesis-patient mismatch (indexed EOA, $<0.85 \mathrm{~cm}^{2} / \mathrm{m}^{2}$ ) at 1 year resolved by 6 years in 


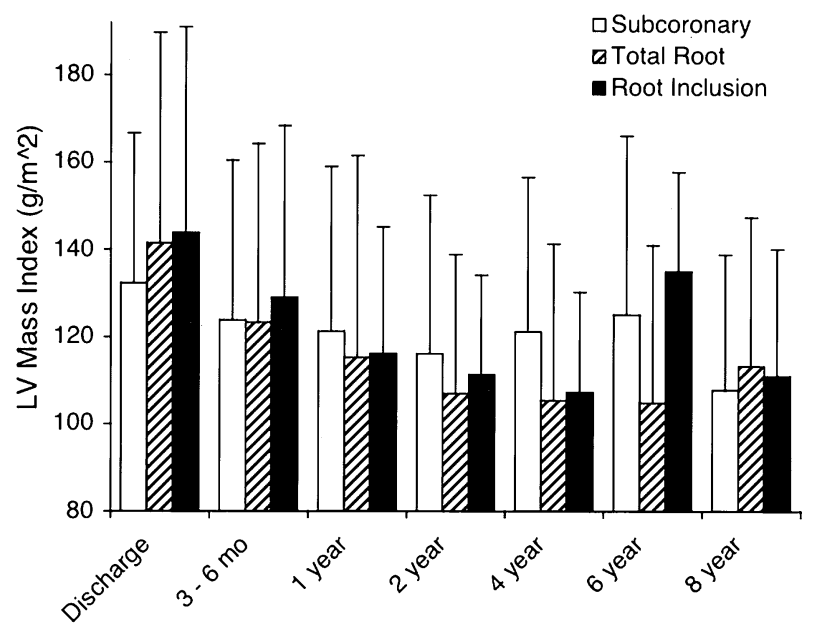

Figure 5. Left ventricular (LV) mass index through 8 years by implant technique.

$13(22 \%)$ of 58 patients and that new prosthesis-patient mismatch developed during the same interval in $25(19 \%)$ of 129 patients without prosthesis-patient mismatch at 1 year.

The rate of adverse events did not differ significantly for patients with prosthesis-patient mismatch early after the operation (indexed EOA $<0.85 \mathrm{~cm}^{2} / \mathrm{m}^{2}$ ) compared with those without patient-prosthesis mismatch. There was a trend that failed to reach statistical significance toward lower overall survival (survival at 8 years of $52.6 \%$ [SE $4.7 \%$ ] vs $65.4 \%$ [SE $4.2 \%$ ], $P=.10)$. There were no differences between groups with or without prosthesis-patient mismatch in rates of valve-related death $(P=.83)$, freedom from reoperation $(P=1.00)$, or freedom from structural valve deterioration $(P=.23)$. Evaluation defining prosthesis-patient mismatch as an indexed EOA of less than $0.65 \mathrm{~cm}^{2} / \mathrm{m}^{2}$ also failed to show significant differences in freedom from adverse events, although a trend was again evident toward lower survival (8-year survival of $46.7 \%$ [SE $12.9 \%$ ] vs $62.0 \%$ [SE $5.8 \%$ ]).

\section{Aortic Regurgitation}

The preponderance of patients in both implant groups had no or trivial AR through 8 years, and no patient had severe AR throughout the follow-up period. Freedom from hemodynamically significant AR is shown in Figure 6. Although the prevalence of AR was extremely low for all implant techniques, patients having undergone subcoronary implantation were 9.6 times more likely than patients who underwent total root implantation to have moderate or severe AR $(P=.03)$.

\section{Discussion}

\section{Hemodynamic Outcomes}

Stentless valves in general have very good hemodynamic characteristics, with low transvalvular gradients and large
TABLE 2. Hemodynamics at 1 year and 6 years after the operation for all valve sizes

\begin{tabular}{lccc}
\hline & Subcoronary & Total root & Root inclusion \\
\hline 1 Year after the operation & & \\
$\mathrm{N}$ & 410 & 134 & 29 \\
$\mathrm{MPG}(\mathrm{mm} \mathrm{Hg})$ & $8.3 \pm 5.4$ & $5.4 \pm 3.7$ & $5.9 \pm 4.0$ \\
EOA $\left(\mathrm{cm}^{2}\right)$ & $1.8 \pm 0.6$ & $2.0 \pm 0.6$ & $2.1 \pm 0.9$ \\
Indexed EOA & $1.0 \pm 0.3$ & $1.1 \pm 0.3$ & $1.1 \pm 0.5$ \\
$\left(\mathrm{~cm}^{2} / \mathrm{m}^{2}\right)$ & & & \\
6 Years after the operation & & \\
$\mathrm{N}$ & 138 & 36 & 15 \\
$\mathrm{MPG}(\mathrm{mm} \mathrm{Hg})$ & $8.8 \pm 6.2$ & $6.0 \pm 3.5$ & $6.2 \pm 3.8$ \\
EOA $\left(\mathrm{cm}^{2}\right)$ & $1.7 \pm 0.5$ & $1.9 \pm 0.8$ & $2.0 \pm 0.7$ \\
Indexed EOA & $1.0 \pm 0.3$ & $1.0 \pm 0.4$ & $1.1 \pm 0.4$ \\
$\left(\mathrm{~cm}^{2} / \mathrm{m}^{2}\right)$ & & & \\
\hline
\end{tabular}

MPG, Mean pressure gradient; $E O A$, effective orifice area.

TABLE 3. Prosthesis-patient mismatch early and at 1 and 6 years after the operation

\begin{tabular}{|c|c|c|c|}
\hline & Subcoronary & Total root & Root inclusion \\
\hline \multicolumn{4}{|c|}{ Indexed EOA $<0.85 \mathrm{~cm}^{2} / \mathrm{m}^{2}$} \\
\hline Early & $255 / 454(56.2 \%)$ & $49 / 148(33.1 \%)$ & $20 / 37(54.1 \%)$ \\
\hline $1 \mathrm{y}$ & $136 / 410(33.2 \%)$ & $30 / 134(22.4 \%)$ & $9 / 29(31.0 \%)$ \\
\hline $6 y$ & $57 / 138(41.3 \%)$ & $10 / 36(27.8 \%)$ & $4 / 15(26.7 \%)$ \\
\hline \multicolumn{4}{|c|}{ Indexed EOA $<0.65 \mathrm{~cm}^{2} / \mathrm{m}^{2}$} \\
\hline Early & $92 / 454(20.3 \%)$ & $17 / 148(11.5 \%)$ & $8 / 37(21.6 \%)$ \\
\hline $1 \mathrm{y}$ & $49 / 410(12.0 \%)$ & $10 / 134(7.5 \%)$ & $4 / 29(13.8 \%)$ \\
\hline $6 y$ & $18 / 138(13.0 \%)$ & $2 / 36(5.6 \%)$ & $2 / 15(13.3 \%)$ \\
\hline
\end{tabular}

EOA, Effective orifice area.

EOAs. The present work confirms that low gradients and large EOAs associated with the Freestyle stentless aortic bioprosthesis are maintained at least 6 years after implantation. Mean gradients remain low, and the average indexed EOA remains at least $1.0 \mathrm{~cm}^{2} / \mathrm{m}^{2}$ for all implant types. Defined as an indexed EOA of less than $0.65 \mathrm{~cm}^{2} / \mathrm{m}^{2}$, the prevalence of prosthesis-patient mismatch was very low throughout the duration of follow-up. However, defined as an indexed EOA of less than $0.85 \mathrm{~cm}^{2} / \mathrm{m}^{2}$, approximately one in 4 patients had prosthesis-patient mismatch 6 years after total root or root inclusion surgery, and approximately $40 \%$ had prosthesis-patient mismatch after subcoronary aortic valve replacement. The clinical implications of these numbers are not clear.

First, there was evidence of excellent LV mass regression early after surgical intervention, reflecting good relief of LV outflow obstruction. Although there was a late increase in LV mass index, it was of very small magnitude and of doubtful clinical relevance. That an increase in LV mass occurred in the setting of maintained low gradients and stable EOA suggests that other factors, such as systemic hypertension, might have played a role in its development. 


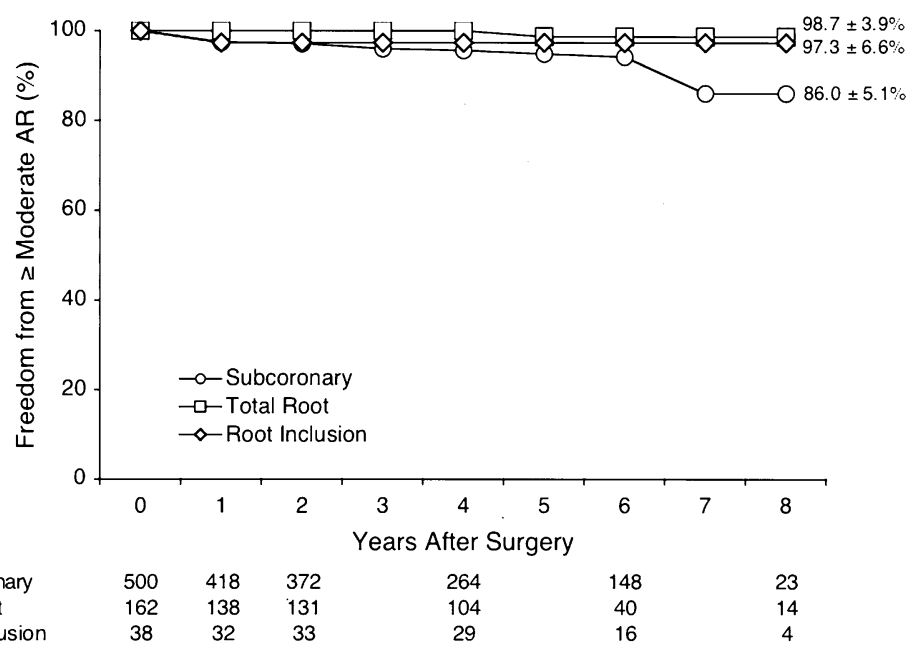

Figure 6. Freedom from moderate or greater aortic regurgitation through 8 years by implant technique. Patients were at higher risk for aortic regurgitation after modified subcoronary replacement $(P=.03)$. Data labels are presented as percentages \pm SE at 8 years. Numbers below the graph represent patients at risk. AR, Aortic regurgitation.

Second, hemodynamics with the Freestyle valve are known to compare favorably with those of stented bioprostheses. ${ }^{14,15}$ As such, the prevalence of prosthesis-patient mismatch that would have occurred in the same population by using another prosthesis is unknown (but could have been higher).

\section{Measures of Durability}

The present report provides reassuring data that the Freestyle valve remains durable through 8 years after the operation. Freedom from structural valve failure, freedom from reoperation, and freedom from hemodynamically significant AR remained favorable through 8 years for the 3 implant groups. However, the population studied was predominantly older than 60 years of age at the time of the operation, and younger patients would be expected to be at greater risk of bioprosthesis failure within the observed follow-up period. Continued assessment will be necessary to define the anticipated durability in the study population.

\section{Differences Between Implant Techniques}

Patients were not randomly assigned to implant technique, and to a large degree, implant technique was influenced by clinical factors, such as the presence of concomitant aortic root pathology. Furthermore, relatively few patients underwent root inclusion aortic valve replacement. As such, the populations in the different implant groups were dissimilar, and comparison between groups is problematic. However, several differences or trends between the groups were evident.
There were no differences between groups in survival or in freedom from valve-related death, reoperation, or structural valve deterioration. Freedom from hemodynamically significant AR was slightly better with the total root technique compared with that after the subcoronary implant technique, possibly related to preservation of the intact porcine root and cusp geometry. Gradients were lower and EOA was higher among patients undergoing total root compared with subcoronary aortic valve replacement. It is possible that the absence of surrounding native aorta results in better hemodynamic performance of the same prosthesis. However, larger prostheses were used among patients in the total root replacement group. Whether these observations are ultimately related to differences in valve sizes implanted or to hypothetic differences in valve performance, decisions regarding implant technique likely will be influenced more by underlying pathology than by small (even if statistically significant) differences in hemodynamics or AR.

\section{Previously Published Data}

Patients included in the present study have been included in earlier reports with shorter follow-up or in reports based on single-center experiences. In 1999, Doty and colleagues ${ }^{1}$ published 5-year data from the multicenter study of the Freestyle aortic valve. Actuarial freedom from all-cause death at 5 years was $72.6 \% \pm 4.8 \%, 70.8 \% \pm 4.7 \%$, and $82.9 \% \pm 4.5 \%$ for the subcoronary, total root, and root inclusion groups, respectively, and overall freedom from valve-related death was $97.0 \%$ at 5 years. At 4 years, gradients were low, and only $4 \%$ of patients had moderate AR. Single-center reports reflecting 5 -year ${ }^{2}$ and 7 -year ${ }^{3}$ 
follow-up reflect similar findings. In 2002, Kon and associates $^{5}$ reported 8-year follow-up from Wake Forest University, where $100 \%$ of implantations were performed as total root replacements. Survival was $59.8 \%$ at 8 years, gradients were low, and there was a $0 \%$ prevalence of hemodynamically significant AR.

The present report extends the multicenter study of patients having undergone aortic valve replacement with the Freestyle stentless bioprosthesis. Overall survival at 8 years is similar to that reported by Kon and associates ${ }^{5}$ for patients undergoing total root replacement. Other measures of clinical outcomes remain favorable, hemodynamics remain well preserved, and valve durability remains intact.

\section{Study Limitations}

The present study is an observational assessment of outcomes. Patients were not randomly assigned to various therapies, and comparison between inherently dissimilar groups is problematic. Clinical follow-up was available through 8 years, and continued study will be necessary as patients reach time points during which valve failure is more likely. Hemodynamic outcomes were measured through 6 years because of limited data available thereafter. Finally, the present study was neither designed nor powered to test the clinical effect of prosthesis-patient mismatch; absence of statistically significant differences in outcomes might be due to sample size.

\section{Conclusions}

The Freestyle stentless aortic bioprosthesis has very good associated hemodynamics that are maintained through 6 years. Measures of clinical outcomes and prosthesis durability remain excellent in multicenter follow-up through 8 years. There are few differences in clinical outcomes between implant groups, although hemodynamics and freedom from AR appear slightly better after total root replacement. The Freestyle stentless aortic root bioprosthesis is a versatile option for aortic valve replacement, with durability that exceeds 8 years in a population predominantly older than 60 years at the time of the operation.

\section{References}

1. Doty DB, Cafferty A, Cartier P, et al. Aortic valve replacement with Medtronic Freestyle bioprosthesis: five year results. Semin Thorac Cardiovasc Surg. 1999;11(suppl 1):35-41.

2. Yun KL, Sintek CF, Fletcher AD, et al. Aortic valve replacement with the Freestyle stentless bioprosthesis: five-year experience. Circulation. 1999;100(suppl II):II17-23.

3. Dagenais F, Cartier P, Dumesnil JG, et al. A single center experience with the Freestyle bioprosthesis: midterm results at the Québec Heart Institute. Semin Thorac Cardiovasc Surg. 2001;13(suppl 1):156-62.

4. Bach DS, Cartier PA, Kon N, Johnson KG, Deeb GM, Doty DB. Impact of implant technique following Freestyle stentless aortic valve replacement. Ann Thorac Surg. 2002;74:1107-14.

5. Kon ND, Riley RD, Adair SM, Kitzman DW, Cordell AR. Eight-year results of aortic root replacement with the Freestyle stentless porcine aortic root bioprosthesis. Ann Thorac Surg. 2002;73:1817-21.

6. Gott JP, Girardot JM, Girardot NM, et al. Refinement of the alpha aminooleic acid bioprosthetic valve anticalcification technique. Ann Thorac Surg. 1997;64:50-8.

7. Walther T, Falk V, Autschbach R, et al. Comparison of different anticalcification treatments for stentless bioprostheses. Ann Thorac Surg. 1998;66(suppl):S249-54.

8. Melina G, Rubens MB, Amrani M, Khaghani A, Yacoub MH. Electron bean tomography for cusp calcification in homograft versus Freestyle xenografts. Ann Thorac Surg. 2001;71(suppl):S368-70.

9. Edmunds LH Jr, Clark RE, Cohn LH, Grunkmeier GL, Miller DC, Weisel RD. Guidelines for reporting morbidity and mortality after cardiac valvular operations. Ann Thorac Surg. 1988;46:257-9.

10. Feigenbaum H. Hemodynamic information derived from echocardiography. In: Feigenbaum H, editor. Echocardiography. 5th ed. Philadelphia: Lea \& Febiger; 1994. p. 181-215.

11. Devereux RB, Alonso DR, Lutas EM, et al. Echocardiographic assessment of left ventricular hypertrophy: comparison to necropsy findings. Am J Cardiol. 1986;57:450-8.

12. Perry GJ, Helmcke F, Nanda NC, et al. Evaluation of aortic insufficiency by Doppler color flow mapping. J Am Coll Cardiol. 1987;9: 952-9.

13. Blais C, Dumesnil JG, Baillot R, Simard S, Doyle D, Pibarot P. Impact of valve prosthesis-patient mismatch on short-term mortality after aortic valve replacement. Circulation. 2003;108:983-8.

14. Yun KL, Jamieson WRE, Khonsari S, Burr LH, Munro AI, Sintek CF. Prosthesis-patient mismatch: hemodynamic comparison of stented and stentless aortic valves. Semin Thorac Cardiovasc Surg. 1999;11(suppl 1):98-102.

15. Dumesnil JG, LeBlanc MH, Cartier PC, et al. Hemodynamic features of the Freestyle aortic bioprosthesis compared with stented bioprosthesis. Ann Thorac Surg. 1998;66(suppl):S130-3.

\section{Appendix}

Study Site Location and Principal Investigator

Hôpital Laval Ste-Foy, Quebec, Canada; Paul A. Cartier, MD

Victoria General Hospital, Halifax, Nova Scotia, Canada; David Ross, MD

Good Samaritan Hospital, Portland, Ore; Albert Krause, MD

Wake Forest University Baptist Medical Center, Winston-Salem, NC; Neal Kon, MD

Kaiser Permanente Los Angeles Medical Center, Los Angeles, Calif; Siavosh Khonsari, MD

Lenox Hill Hospital, New York, NY; V. A. Subramanian, MD

Southwest Washington Medical Center, Vancouver, Wash; Albert Krause, MD

LDS Hospital, Salt Lake City, Utah; Donald B. Doty, MD 